\title{
Increased Time To Peak Drug Blood Concentration
}

National Cancer Institute

\section{Source}

National Cancer Institute. Increased Time To Peak Drug Blood Concentration. NCI

Thesaurus. Code C54604.

Increased period of time required for the concentration or amount of drug in the body to be reduced to exactly one-half of a given concentration or amount. 